\title{
KOMUNIKASI VERBAL DALAM ALQURAN
}

\author{
Irma Yusriani Simamora
}

(Dosen Fakultas Dakwah dan Komunikasi UIN-SU Medan)

\begin{abstract}
Abstrak
Komunikasi verbal adalah komunikasi yang menggunakan simbol-simbol atau katakata, baik yang dinyatakan secara oral atau lisan maupun secara tulisan. Komunikasi verbal dapat dibedakan atas komunikasi lisan dan komunikasi tulisan. Komunikasi lisan dapat didefinisikan sebagai suatu proses di mana seorang pembicara berinteraksi secara lisan dengan pendengar untuk mempengaruhi tingkah laku penerima. Komunikasi verbal yang terdapat di dalam Alquran mempunyai 3 karakteristik, yaitu: memanfaatkan tulisan, memanfaatkan suara dan merangsang kualitas dan kuantitas perkataan. Sedangkan pola komunikasi verbal dalam Alquran di antaranya berbentuk pertanyaan, penjelasan dan penegasan.
\end{abstract}

Kata Kunci: Komunikasi Verbal dan Alquran

\section{A. Pendahuluan}

Komunikasi merupakan salah satu aspek terpenting dan kompleks bagi kehidupan manusia. Manusia sangat dipengaruhi oleh komunikasi yang dilakukannya dengan manusia lain, baik yang sudah dikenal maupun yang tidak dikenal sama sekali. Komunikasi memiliki peran yang sangat vital bagi kehidupan manusia, karena itu perlu diberikan perhatian yang seksama terhadap komunikasi.

Komunikasi verbal antara manusia kadang dihiasi pertanyaan, dialog, sumpah, janji, ancaman dan sebagainya. Hal itu dimaksudkan agar pesan yang disampaikan mengenai sasaran dan efektif. Allah Swt dalam mengkomunikasikan pesan-pesan-Nya juga menggunakan bahasa dan gaya bahasa manusia, tujuannya agar pesan-pesan tersebut dapat diterima, diperhatikan, dipedomani dan dilaksanakan dengan baik.

Dalam tulisan ini akan dibicarakan tentang komunikasi verbal dalam Alquran, karakteristik verbalistik Alquran dan pola-pola komunikasi verbal dalam Alquran dengan menjadikan Q.S An Nisa' ayat 63 dan Thaha ayat 44 sebagai acuan penafsiran secara tematik.

\section{B. Pengertian Komunikasi Verbal}

Sebelum berbicara tentang komunikasi verbal, tentu perlu dimengerti terlebih dahulu apa yang dimaksud dengan komunikasi. Istilah komunikasi berpangkal dari perkataan 
latin Communisyang artinya membuat kebersamaan atau membangun kebersamaan antara dua orang atau lebih. Komunikasi juga berasal dari akar kata dalam bahasa latin Communico yang atinya membagi. ${ }^{1}$

Sebuah definisi singkat dibuat oleh Harold D. Lasswell bahwa cara yang tepat untuk menerangkan suatu tindakan komunikasi ialah menjawab pertanyaan "Siapa yang menyampaikan, apa yang disampaikan, melalui saluran apa, kepada siapa dan apa pengaruhnya. ${ }^{2}$ Berdasarkan paradigma Lasswell tersebut, komunikasi adalah proses penyampaian pesan oleh komunikator kepada komunikan melalui media yang menimbulkan efek tertentu ${ }^{3}$.

Everet M. Rogers seorang pakar Sosiologi Pedesaan Amerika yang telah banyak memberi perhatian pada studi riset komunikasi, khususnya dalam hal penyebaran inovasi membuat defenisi bahwa: Komunikasi adalah proses di mana suatu ide dialihkan dari sumber kepada satu penerima atau lebih, dengan maksud untuk mengubah tingkah laku mereka."

Defenisi ini kemudian dikembangkan oleh Rogers bersama D. Lawrence Kincaid sehingga melahirkan suatu definisi baru yang menyatakan bahwa : Komunikasi adalah suatu proses di mana dua orang atau lebih membentuk atau melakukan pertukaran informasi dengan satu sama lainnya, yang pada gilirannya akan tiba pada saling pengertian yang mendalam. ${ }^{4}$

Sedangkan yang dimaksud dengan komunikasi verbal adalah komunikasi yang menggunakan simbol-simbol atau kata-kata, baik yang dinyatakan secara oral atau lisan maupun secara tulisan. ${ }^{5}$

Komunikasi verbal dapat dibedakan atas komunikasi lisan dan komunikasi tulisan. Komunikasi lisan dapat didefinisikan sebagai suatu proses di mana seorang pembicara berinteraksi secara lisan dengan pendengar untuk mempengaruhi tingkah laku penerima. ${ }^{6}$

\section{Komunikasi Verbal Dalam Alquran}

\section{Karakteristik Verbalistik Alquran}

Komunikasi verbal yang terdapat di dalam Alquran, sebagaimana yang disampaikan oleh Muhammad Djarot Sensa ${ }^{7}$ mempunyai 3 karakteristik, yaitu:

${ }^{1}$ Hafied Cangara, Pengantar Ilmu Komunikasi, (Jakarta: PT. RajaGrafindo Persada, 2009), h. 18.

${ }^{2}$ Cangara, Pengantar..., h. 18-19.

${ }^{3}$ Onong Uchjana Effendy, Ilmu Komunikasi Teori dan Praktek, (Bandung: PT. Remaja Rosdakarya, cet. 18, 2004), h. 10.

${ }^{4}$ Cangara, Pengantar ..., h. 20.

${ }^{5}$ Arni Muhammad, Komunikasi Organisasi, (Jakarta: PT. Bumi Aksara,Ed. 1 cet. 10, 2009), h. 95.

${ }^{6}$ Ibid, h. 95-96.

${ }^{7}$ Muhammad Djarot Sensa, Komunikasi Qur'aniyah, (Bandung: Pustaka Islamika, cet.1, 2005), h. $64-65$. 
a. Memanfaatkan Tulisan

Dikarenakan Alquran memiliki pengertian bacaan dan juga disebutkan dengan alKitab yang mempunyai pengertian buku yang berisikan tulisan-tulisan, maka tidak pelak bahwa isi yang berbentuk fisik dari Alquran adalah tulisan-tulisan. Pemanfaatan tulisan ini tampaknya sebagai salah satu upaya yang oleh Alquran sendiri dinyatakan: Faqra'u ma tayassara minal quran, yang terjemahannya adalah; Maka bacalah Alquran yang telah serba dimudahkan. Q.S. (73) al-Muzammil ayat 20.

b. Memanfaatkan Suara

Suara sangat penting dalam memberikan pengaruh terhadap pikiran, akal, hati dan jiwa manusia. Meskipun Alquran memanfaatkan suara, tidak secara eksplisit disampaikan di dalam bentuk tulisan. Melainkan dengan berisikan perintah untuk mengucapkan atau kalau dibaca akan menimbulkan suara. Sejumlah perintah yang menimbulkan suara adalah dengan memakai kata-kata atau istilah-istilah seperti katakanlah dan bacakanlah.

c. Merangsang kualitas dan kuantitas perkataan

Alquran mengandung banyak perkataan, yang berasal dari Allah S.W.T secara langsung, ucapan dari para Nabi dan Rasul, orang-orang mukmin dan bahkan orang-orang kafir sekalipun. Perbedaan yang dapat diambil dari jenis-jenis perkataan itu adalah ada yang menggunakan siapa pelaku yang mengatakan atau memerintahkan untuk berkata-kata, sampai dengan juga disebutkan apa isi dari perkataan yang disampaikan. Suatu contoh misalnya, perkataan-perkataan dari Allah S.W.T., para Rasul, para Nabi dan para mukmin, adalah perkataan-perkataan yang berisikan ajakan sampai dengan penekanan, bahwa Allah S.W.T itu Esa dan harus menyembah-Nya tanpa melibatkan sesuatu apapun. Sementara dari orang-orang yang tidak sama, maka perkataanperkataannya bernada pengingkaran, pelecehan, olok-olok, perlawanan dan sejenisnya.

Nah, di dalam perintah-perintah untuk mengatakan atau berkata-kata, Alquran ternyata tidak mengajarkan hal-hal yang bersifat buruk. Bahkan apabila menghadapi gangguan dan penghalang yang demikian menyakitkan pun, Alquran menekankan perlunya melakukan perkataan atau penggunaan lisan yang bersifat menyelamatkan. Seperti bunyi ayat Alquran berikut:

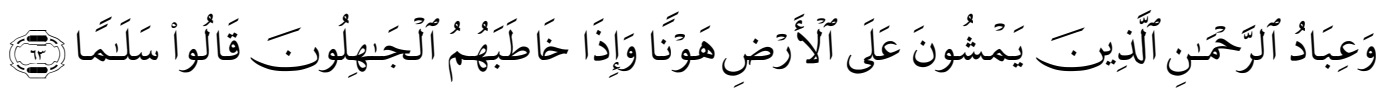

Artinya: Dan hamba-hamba sang Pemurah, adalah orang-orangyang berjalan di muka bumi denganrendah hati, dan apabila orang-orangjahil menyapamereka, merekamengucapkan kata-kata yang menyelamatkan.(Q.S. al-Furqan/25: 63) ${ }^{8}$.

${ }^{8}$ Departemen Agama RI, Alquran dan Terjemahnya,(Bandung: CV. Penerbit J-ART, 2005), h. 366. 


\section{Ayat-Ayat Komunikasi Verbal Dalam Alquran}

Alquran sebagai kitab dakwah yang mengajak manusia ke jalan yang lebih baik dan lurus tidak terlepas dari nuansa komunikasi verbal, sebuah ragam komunikasi yang menggunakan simbol-simbol atau kata-kata, baik yang dinyatakan secara oral atau lisan maupun secara tulisan. Dalam banyak ayat disebutkan komunikasi-komunikasi yang bernuansa verbal. Ayat-ayat tersebut di antaranya:

a. Q.S: An Nisa' 63

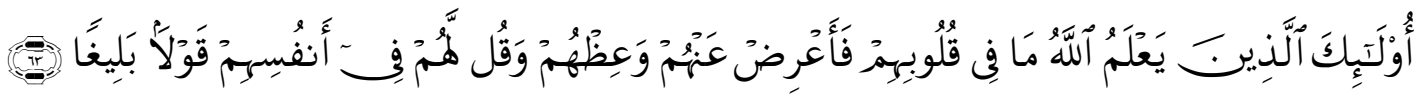

Artinya: "Merekaitu adalah orang-orangyang Allah mengetahuiapa yang di dalam hati mereka.karena itu berpalinglahkamu dari mereka, dan berilah merekapelajaran, dan Katakanlah kepada merekaPerkataan yang berbekaspada jiwa mereka. ${ }^{\text {}}$

b. Thaha :44

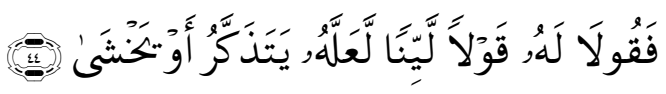

Artinya: Maka berbicaralah kamu berdua kepadanya dengan kata-kata yang lemah lembut, mudah-mudahania ingat atau takut."10

Hal-hal yang dikandung oleh kedua ayat di atas dikemukakan sebagai berikut:

\section{a. Karakteristik An Nisa' ayat 63 dan Thaha ayat 44}

Bila kita membaca kembali karakteristik verbalistik Alquran yang dikemukakan oleh Muhammad Djarot Sensa ${ }^{11}$, kita dapat menyimpulkan bahwa kedua ayat yang sedang kita perbincangkan termasuk ke dalam katagori yang kedua yaitu memanfaatkan suara.

Pemanfaatan suara tersebut tercermin pada ungkapan "Katakanlah kepada mereka Perkataan yang berbekas pada jiwa mereka" dan "Maka berbicaralah kamu berdua kepadanya dengan kata-kata yang lemah lembut".

Katakanlah kepada orang-orang munafik yang menyembuyikan niat dan maksud jahat mereka ungkapan yang langsung menyentuh hati. Dengan ungkapan itu mereka akan kembali ke jalan yang benar. ${ }^{12}$ Dan, berbicaralah kamu berdua wahai Musa dan Harun kepada Fir'aun dengan kata-kata yang lemah lembut. Katakanlah, "Wahai Firuan, sesungguhnya engkau punya Tuhan, tempat kembali, di hadapanmu menunggu surga dan neraka. ${ }^{13}$

${ }^{9}$ Ibid, h. 89.

${ }^{10}$ Ibid, h. 315.

${ }^{11}$ Sensa, Komunikasi..., h. $64-65$.

${ }^{12}$ Sayyid Quthub, Fi Zhilalil Quran, (Maktabah Syamilah).

${ }^{13}$ Ismail bin Umar bin Katsir al-Qurasyi, Tafsir al-Quran al-Azhim, (tt: Dar at-Thayyibah, juz: 5, 1999), h. 294. 
Kedua ayat di atas berisi perintah untuk mengatakan perkataan yang berbekas dalam jiwa dan lemah lembut. Perintah itu tentu baru akan terealisasi bila dinyatakan dengan suara.

\section{b. Komunikasi positif verbal kunci kesuksesan dakwah}

Ayat-ayat di atas mengungkapkan urgensi pemakaian komunikasi verbal yang santun dalam menyampaikan dakwah kepada komunikan. Karena pemakaian corak komukasi tersebut akan mengantarkan kepada suksesnya dakwah. Terlebih bahwa komunikator dalam Islam ditekankan agar berbicara secara lemah lembut ${ }^{14}$. Pada ayat pertama misalnya, terdapat firman Allah yang berbunyi, "Baligh" (Perkataan yang berbekas).

Term baligh secara bahasa berasal dari kata balagha, yang berarti sampainya sesuatu kepada tujuan yang dimaksud, baik tempat, waktu, atau apa saja yang terukur. Sementara itu, ada banyak penjelasan dari para mufassir mengenai pemakanaan term baligh secara istilahi pada ayat ini, sebagaimana berikut ini:

a. Ibnu Katsir (700-774 H ): Perkataan yang dapat merubah prilaku komunikan.

b. Al Alusi $(1270 \mathrm{H})$ : Perkataan yang mempengaruhi sanubari komunikan dan sesuai dengan keadaan.

c. Al Jazari: Perkataan penuh makna dan lugas sehingga menembus jantung hati komunikan.

d. Ismail Haqqi (1137 H): Perkataan yang menyentuh dan berpengaruh pada hati sanubari komunikan.

e. Al Maraghi: perkataan yang menyentuh hati yang dapat menggerakkan komunikan. ${ }^{15}$

Melihat beberapa penjelasan para mufassir di atas, Qaul baligh dapat dimaknai sebagai komunikasi dengan menggunakan bahasa yang efektif, tepat sasaran, komunikatif, sesuai dengan intlektualitas komunikan, mudah dimengerti, langsung ke pokok masalah, dan tidak berbelit-belit atau bertele-tele. Dengan demikian seorang komunikator dikatakan telah menggunakan bentuk komunikasi baligh apabila kriteria-kriteria di atas ditempuh sehingga mampu menggerakkan dan merubah komunikan.

Bentuk komunikasi sebagaimana dikemukakan di atas mendapat penegasan pula dari firman Allah:

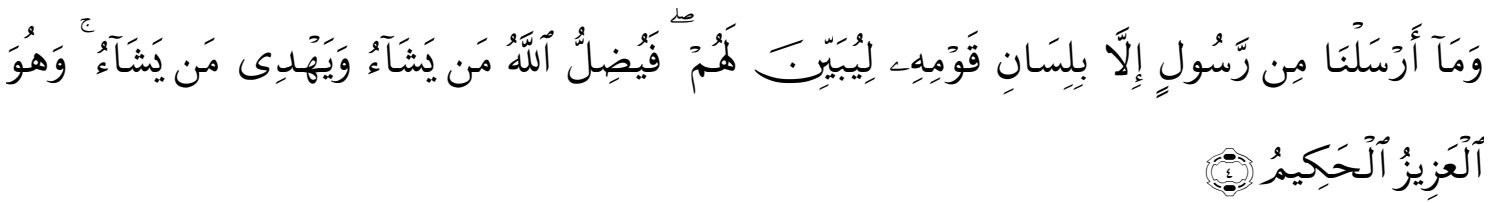

${ }^{14}$ Syukur Khalil, Komunikasi Islam, (Bandung: Citapustaka Media, cet. 1, 2007), h. 8.

${ }^{15}$ Lajnah Pentashihan Mushaf Al Quran Badan Litbang Dan Diklat Kementerian Agama, Komunikasi dan Informasi (Tafsir Alquran Tematik), (Jakarta: cet. 1, 2011), h. 175. 
Artinya: Kami tidak mengutusseorangrasulpun, melainkan denganbahasa kaumnya, supaya ia dapat memberipenjelasandenganterang kepadamereka.Maka Allah menyesatkan siapa yang Dia kehendaki,dan memberipetunjukkepadasiapa yang Dia kehendaki.Dan Dialah Tuhan Yang Maha Kuasa lagi Maha Bijaksana. (Q.S: Ibrahim: 4)

Selanjutnya, pengukuhan akan urgensi pemakaian komunikasi verbal positif guna menggapai kesuksesan dalam berdakwah, tertuang secara jelas dalam ayat yang kedua, yaitu surat Thaha ayat 44 .

Hamka menuturkan, di dalam pangkal ayat 44 ini Tuhan telah memberikan suatu petunjuk dan arahan yang penting dalam memulai dakwah kepada orang yang telah sangat melampaui batas itu. Dalam permulaan berhadap-hadapan, kepada orang yang seperti itu janganlah langsung dilakukan sikap yang keras, melainkan hendaklah mulai dengan mengatakan sikap lembah lembut, perkataan yang penuh dengan suasana kedamain. Sebab kalau dari permulaan konfrontasi (berhadap muka dengan muka) si pendakwah telah melakukan amar ma'ruf nahi munkar dengan secara keras, blak-blakan, tidaklah akan tercapai apa yang dimaksud.

Meskipun di dalam ilmu Allah ta'ala sendiri pasti sudah diketahui bahwa Firaun itu sampai saat terakhir tidak akan mengaku tunduk, tetapi Tuhan telah memberikan tuntunan kepada Rasul-Nya, ataupun kepada siapa saja yang berjuang melanjutkan rencana NabiNabi, bahwa pada langkah yang pertama janganlah mengambil sikap menantang. Mulailah dengan kata yang lemah lembut: Mudah-mudahan ingatlah dia, ataupun takut.

Sebabnya ialah bahwa di dalam sudut bawah dalam jiwa manusia, yang mana jua pun orangnya senantiasa masih tersimpan maksud yang baik dan fikiran yang sihat. ${ }^{16}$

Hal senada juga disampaikan oleh Qurasih Shihab, Firman Allah yang berbunyi "Maka berbicaralahkamu berduadengankata-kata yanglemahlembut"menjadi dasar tentang perlunya sikap bijaksana dalam berdakwah yang antara lain ditandai dengan ucapan-ucapan sopan yang tidak menyakitkan hati sasaran dakwah. Karena Firaun saja, yang demikian durhaka, masih juga harus dihadapi dengan lemah lembut. Memang dakwah pada dasarnya adalah ajakan lemah lembut. Dakwah adalah ajakan menyampaikan hidayah. ${ }^{17}$

Berikut ini terdapat riwayat yang mengisahkan komunikasi verbal yang dilakoni oleh Rasululullah:

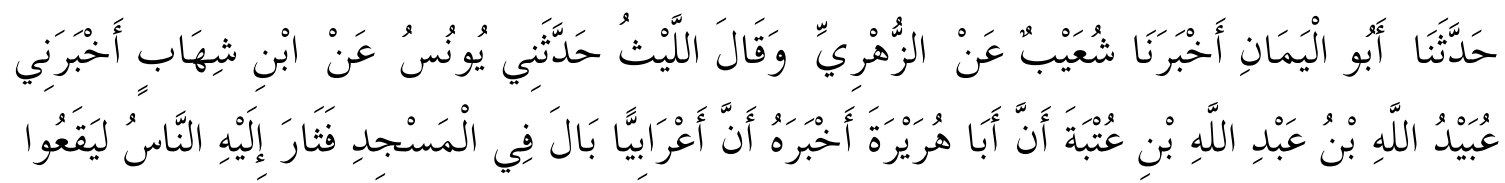

${ }^{16}$ Hamka, Tafsir Al Azhar, (Jakarta: Pustaka Panjimas, juz 16, 1983), h. 159.

${ }^{17}$ M. Quraish Shihab, Tafsir Al Misbah Pesan, Kesan, dan Keserasianal-Quran, (Jakarta: Lentera hati, cet. 1, 2009), h. 594. 


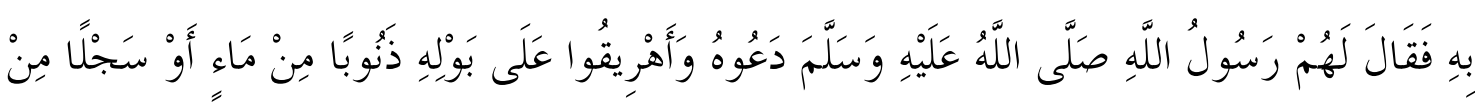

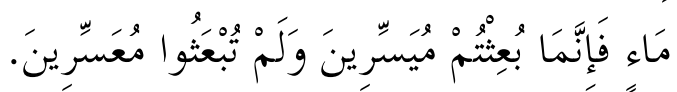

Artinya: Abual-Yaman menceritakankepadakami, Syu'aib menceritakankepadakami dari az-Zuhri, al-Laits berkata, "Yunus menceritakankepadaku dari Ibnu Syihab, Ubaidullah bin Abdullahbin 'Utbah memberiatahukankepadakubahwsanyaAbuHurairah menceritakan: Suatu ketika, seorangArab Badui buang air kecildi dalam mesjid(tepatnya di sudutmesjid). Orang-oranglantas berdiriuntuk memukulinya.Namun, RasulullahS.A.Wmencegahnyadan bersabda,"Biarkanlah dia, siramlah air kencingnyadenganseemberatau segayungair, Sesungguhrya kamu ditampilkanketengah-tengahumat manusia untukmemberikemudahanbukan membuat kesukaran,"18

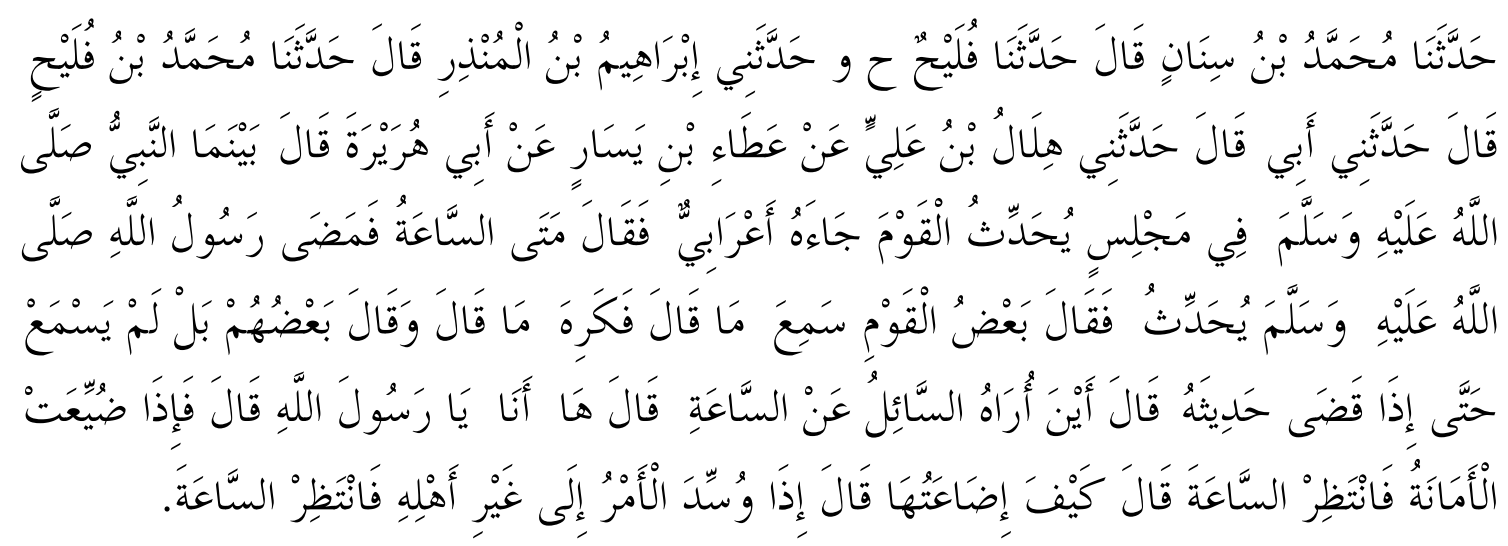

Artinya: Muhammadbin Sinan menceritakankepadakami, ia berkata, Fulaih menceritakan kepadakami, hadis, dan Ibrahim bin al-Mundzirmenceritakankepadaku,ia berkata, Muhammad bin Fulaih menceritakankepadakami, ia berkata, bapakkumenceriatakankepadaku, ia berkata, Hilal bin Ali menceritakankepadakudari 'Atha bin Yasar dari AbuHurairah, ia berkata, "Ketika Nabi berada di tengah-tengahmajelis sedangberbiancang-bincangdengansuatu kaum tibatiba seorangArab Baduwimendatangibeliau seraya bertanya, "Kapankah kiamat?." Namun Rasul tetap saja melanjutkan perbincangannya.Di antara orang yang ada berkata, "Rasul mendengarpertnyaan tersebutnamun ia tidak menyukainya."Sebagianlain berkata, "rasul tidak dengarpertanyaan tadi." Usai dari peribancangannya,Rasulullah pun bertanya, "Mana orangyang telah bertanya tentanghari kiamat tadi?." Orang itu pun menjawab, "Saya wahai Rasulullah." Rasulullah bersabda, "Apabila amanah telah disia-siakan maka nantikanlah kehadiran kiamat." Orang itu bertanya, "Bagaimana bentukpenyia-nyiaannya?."Rasulullah menjawab, "Apabila suatu urusan diserahkankepadaorangyang tidak ahlinya maka tunggulah saatnya kiamat."19

${ }^{18}$ Muhammad bin Ismail bin Ibrahim bin Al Mughirah Al Bukhari, Al Jami' As Shahih Al Musnad min Hadisi Rasulillah, (Kairo: Dar ar-Raiyan, 1988), h. 2270.

${ }^{19}$ Al Bukhari, Al Jami' As Shahih, h. 103. 


\section{Pola Komunikasi Verbal Dalam Alquran}

Komunikasi verbal dalam Alquran mempunyai beberapa pola, di antaranya:

\section{a. Pertanyaan}

Dalam percakapan sehari-hari, ungkapan yang berbentuk kata tanya sering digunakan, bahkan merupakan ungkapan pokok dalam komunikasi tentang sesuatu yang tidak dan belum jelas maknanya.

Salah satu ciri dari ayat-ayat Allah S.W.T di dalam Alquran yang menggunakan metode bertanya adalah dengan menggunakan kata Alam tara, yang kalau dihitung akan mencapai sebanyak 31 buah. Salah satu di antaranya berbunyi sebagaimana di bawah ini ${ }^{20}$ :

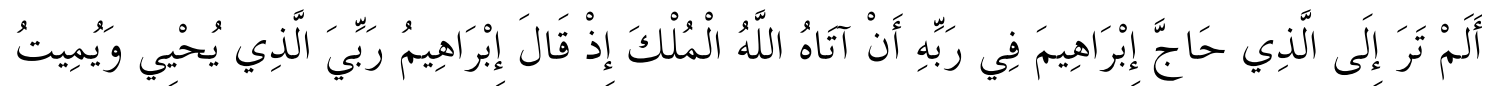

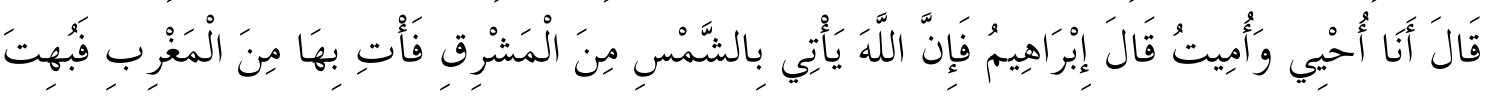

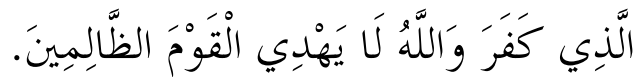

Artinya: Apakah kamu tidak memperhatikanorang yang mendebatIbrahim tentang Tuhannya (Allah) karena Allah telahmemberikankepadaorang itu pemerintahan(kekuasaan). Ketika Ibrahim mengatakan: "Tuhanku ialah Yang menghidupkandan mematikan," orang itu berkata: "Saya dapat menghidupkandan mematikan."Ibrahimberkata: "Sesungguhnya Allah menerbitkanmatahari dari timur, maka terbitkanlah dia dari barat," lalu terdiamlah orang kafir itu; dan Allah tidak memberipetunjukkepada orang-orangyang zalim²1.

\section{b. Penjelasan}

Pola ini pada umumnya ditujukan di dalam memberikan jawaban terhadap persoalan atau pertanyaan yang diajukan kepada Nabi Muhammad S.A.W sehingga diharapkan akan menemukan pemahaman yang memang dimaksudkan oleh Allah S.W.T.

Al Bazzar meriwayatkan dari Ibnu Abbas bahwa pertanyaan generasi salaf kepada Nabi S.A.W yang direkam Alquran hanya 12 masalah, yakni terdapat dalam Al Baqarah: 186, 189, 215, 217, 219, 220, 222, Al Maidah: 4, Al A'raf: 187, Al Anfal: 1, Al Isra': 85, Al Kahf: 83, Thaha: 105, dan An Naziat: 42.22

Firman Allah dalam Surat Al A'raf ayat 187 dan Al Isra' ayat 85 berikut ini misalnya:

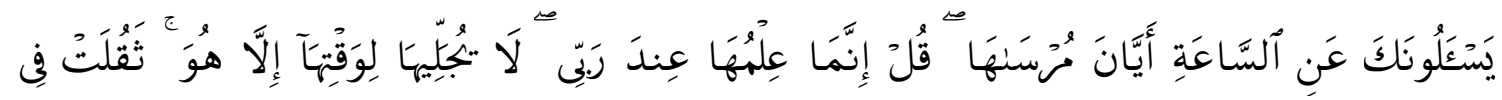

\footnotetext{
${ }^{20}$ Sensa, Komunikasi..., h. 130.

${ }^{21}$ Departemen Agama RI, Alquran..., h. 44.

${ }^{22}$ Jalaluddin As Suyuthi, Al Itqan fi Ulumil Quran, (Bierut: Dâr al-Kutub al-'Ilmiyah, juz 1, 1991),
} h. 577. 


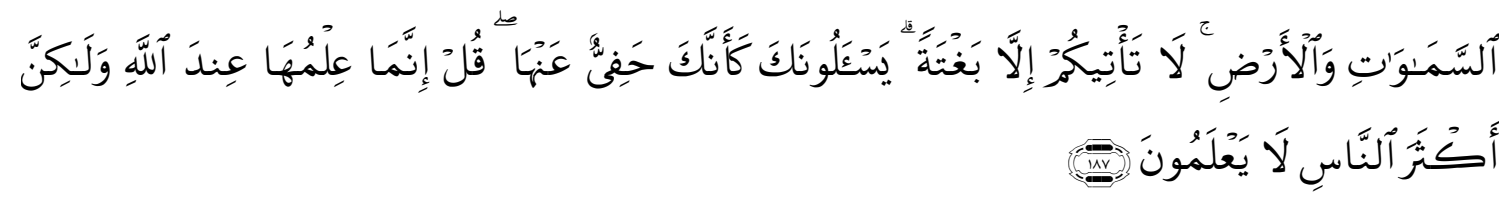

Artinya: Merekamenanyakankepadamutentangkiamat: "Bilakah terjadinya?”Katakanlah: "Sesungguhnyapengetahuantentangkiamat itu adalah pada sisi Tuhanku; tidak seorangpun yang dapat menjelaskanwaktu kedatangannyaselainDia. Kiamat itu amat berat (huru haranya bagi makhluk) yang di langit dan di bumi. Kiamat itu tidak akan datang kepadamumelainkan dengantiba-tiba." Merekabertanyakepadamuseakan-akan kamu benar-benarmengetahuinya. Katakanlah: "Sesungguhnyapengetahuantentangbari kiamat itu adalah di sisi Allah, tetapi kebanyakan manusia tidak mengetahui." ${ }^{23}$

Diriwayatkan oleh Ibnu Jarir dan lain-lain yang bersumber dari Ibnu Abbas, bahwa Ibnu Abi Qusyair dan Samuel bin Zaid menghadap Rasululullah S.A.W dan bertanya, "Sekiranya engkau benar-benar sebagai Nabi sesuai dengan pengakuanmu, coba terangkan kepada kami kapan waktunya kiamat, karena kami tahu kapan akan terjadinya." Maka Allah menurunkan ayat ini yang menegaskan bahwa tak seorang pun mengetahui waktunya, kecuali Allah, dan akan tiba sekonyong-konyong. ${ }^{24}$

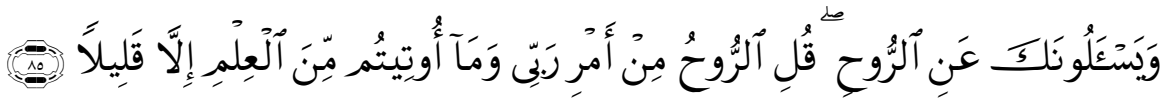

Artinya: Dan merekabertanya kepadamutentangroh. Katakanlah: "Rohitu termasuk urusan Tuhan-ku, dan tidaklah kamu diberipengetahuanmelainkan sedikit.' ${ }^{25}$

Diriwayatkan oleh Al Bukhari yang bersumber dari Ibnu Mas'ud bahwa pada suatu hari Nabi S.A.W berjalan di Madinah ditemani oleh Ibnu Mas'ud dan lewat di depan segolongan kaum Yahudi. Salah seorang di antara mereka berkata, "Mari kita bertanya kepadanya." Mereka pun bertanya, "Coba terangkan kepada kami tentang ruh." Nabi S.A.W berdiri sesaat seraya mengangkat kepala ke langit. Terlihat beliau sedang diberi wahyu, kemudian beliau membacakan ayat, "Qul Ar Ruhu min Amri Rabbi... ${ }^{26}$

\section{c. Penegasan}

Pola ini biasanya dengan menggunakan kata 'Ilamu yang artinya ketahuilah atau Fa'lamu yang artinya maka ketahuilah. Untuk yang menggunakan'Ilamu ditemukan sebanyak 21 buah, sedangkan yang mencantumkan kata Fa'lamu dijumpai sebanyak 6 buah. ${ }^{27}$

${ }^{23}$ Departemen Agama RI, Alquran..., h. 175.

${ }^{24}$ Jalaluddin As Suyuthi, Lubabun Nuqul fi Asbabin Nuzul, (Kairo: Maktabah As Safa, 2002), h. 126.

${ }^{25}$ Departemen Agama RI, Alquran..., h. 291.

${ }^{26}$ As Suyuthi, Lubabun Nuqul..., h. 173.

${ }^{27}$ Sensa, Komunikasi..., h. 132. 
Di antara ayat-ayat tersebut adalah sebagai berikut:

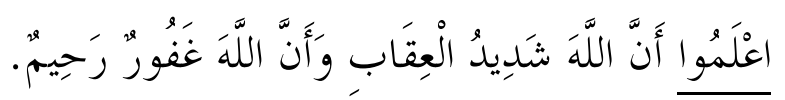

Artinya: Ketahuilah, bahwa sesungguhnyaAllah amat berat siksa-Nya dan bahwa sesungguhnyaAllah Maha Pengampunlagi Maha Penyayang. ${ }^{28}$

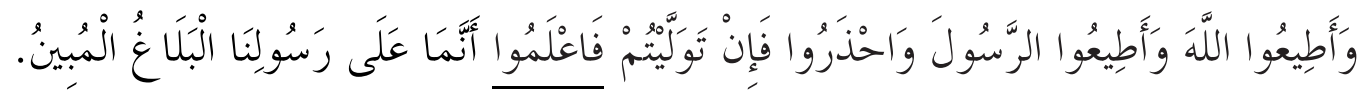

Artinya: Dan taatlah kamu kepadaAllah dan taatlah kamu kepada Rasul-(Nya) dan berhati-hatilah. Jika kamu berpaling, maka ketahuilah bahwa sesungguhnyakewajiban Rasul Kami, hanyalah menyampaikan (amanat Allah) denganterang. ${ }^{29}$

\section{E. Penutup}

Komunikasi verbal adalah komunikasi yang menggunakan simbol-simbol atau katakata, baik yang dinyatakan secara oral atau lisan maupun secara tulisan.

Komunikasi verbal yang terdapat di dalam Alquran mempunyai 3 karakteristik, yaitu: memanfaatkan tulisan, memanfaatkan suara dan merangsang kualitas dan kuantitas perkataan. Sedangkan pola komunikasi verbal dalam Alquran di antaranya berbentuk pertanyaan, penjelasan dan penegasan.

Ayat-ayat di atas mengungkapkan urgensi pemakaian komunikasi verbal yang santun dalam menyampaikan dakwah kepada komunikan. Karena pemakaian corak komukasi tersebut akan mengantarkan kepada suksesnya dakwah. Terlebih bahwa komunikator dalam Islam ditekankan agar berbicara secara lemah lembut.

\footnotetext{
${ }^{28}$ Departemen Agama RI, Alquran..., h.125.

${ }^{29}$ Ibid, h. 124.
} 


\section{DAFTAR PUSTAKA}

Al Bukhari, Muhammad bin Ismail bin Ibrahim bin Al Mughirah. 1988. Al Jami' As Shahih Al Musnad min Hadisi Rasulillah. Kairo: Dar ar-Raiyan.

Cangara Hafied. 2009. Pengantar Ilmu Komunikasi. Jakarta: PT. RajaGrafindo Persada.

Departemen Agama RI. 2005. Alquran dan Terjemahnya. Bandung : CV. Penerbit J-ART.

Effendy, Onong Uchjana. 2004, Ilmu Komunikasi Teori dan Praktek. Bandung: PT. Remaja Rosdakarya, cet. 18.

Hamka. 1983. Tafsir Al Azhar. Jakarta: Pustaka Panjimas.

Ismail bin Umar bin Katsir al-Qurasyi. 1999. Tafsir al-Quran al-Azhim. tt: Dar at-Thayyibah.

Khalil, Syukur. 2007. Komunikasi Islam. Bandung: Citapustaka Media.

Lajnah Pentashihan Mushaf Al Quran Badan Litbang Dan Diklat Kementerian Agama. 2011. Komunikasi dan Informasi (Tafsir Alquran Tematik). Jakarta.

Muhammad, Arni. 2009. Komunikasi Organisasi. Jakarta: PT. Bumi Aksara,Ed.

Quthub, Sayyid. Fi Zhilalil Quran. (Maktabah Syamilah).

As Suyuthi, Jalaluddin. 1991. Al Itqan fi Ulumil Quran, Bierut: Dâr al-Kutub al-'Ilmiyah. . 2002. LubabunNuqul fi Asbabin Nuzul. Kairo: Maktabah As Safa.

Shihab, M. Quraish. 2009. Tafsir Al Misbah Pesan, Kesan, dan Keserasianal-Quran. Jakarta: Lentera Hati.

Sensa, Muhammad Djarot. 2005. KomunikasiQur'aniyah. Bandung: Pustaka Islamika. 